\title{
Preferences for participation in shared decision making of psychiatric outpatients with affective disorders
}

\author{
Carlos De las Cuevas ${ }^{1,2 *}$, Wenceslao Peñate ${ }^{3}$ \\ ${ }^{1}$ Department of Psychiatry, University of La Laguna, San Cristóbal de La Laguna, Spain \\ ${ }^{2}$ REDISSEC (Red de Investigación en Servicios de Salud y Enfermedades Crónicas), Santa Cruz de Tenerife, Spain \\ ${ }^{3}$ Department of Personality, Assessment and Psychological Treatments, University of La Laguna, San Cristóbal de La Laguna, Spain \\ Email: ${ }^{*}$ cdelascuevas@gmail.com
}

Received 5 November 2013; revised 26 November 2013; accepted 4 December 2013

Copyright (C) 2014 Carlos De las Cuevas, Wenceslao Peñate. This is an open access article distributed under the Creative Commons Attribution License, which permits unrestricted use, distribution, and reproduction in any medium, provided the original work is properly cited. In accordance of the Creative Commons Attribution License all Copyrights (C) 2014 are reserved for SCIRP and the owner of the intellectual property Carlos De las Cuevas, Wenceslao Peñate. All Copyright ( $~ 2014$ are guarded by law and by SCIRP as a guardian.

\section{ABSTRACT}

Objective: To assess preferences for participation in shared decision making in a representative sample of psychiatric outpatients with affective disorders and to understand how clinical and socio-demographic variables influence patients' preferences for participation. Method: A cross-sectional survey of 172 consecutive psychiatric outpatients with affective disorders attending at Community Mental Health Care setting was carried out. Patients expressed preferences on each of 3 aspects of decision making (seeking information, discussing options, making the final decision). The "CGI Severity and Improvement Scales" and the “Beck Depression Inventory" scale were used for severity assessment. Additionally the "Drug Attitude Inventory", the "Beliefs about Medicine Questionnaire" and the "Leeds Attitude toward Concordance Scale" were applied to all participants. Effects of variables considered on preferences were assessed using proportional odds regression models. Results: We registered a high response rate of $85 \%$. Nearly all patients (91\%) preferred to leave final decisions to their treating psychiatrists and $87 \%$ preferred to rely on psychiatrists for medical knowledge rather than seeking their own information. In contrast, $81 \%$ of patients preferred to be offered options and to be asked their opinion by their doctors. Gender, age, educational level, number of psychotropics used and belief about psychiatric medication overuse were significant predictors in decision making dimensions considered. Conclusion: Shared decision making approach of patients with affective disorder must take

"Corresponding author. into consideration a more doctor-directed approach preferred by the patients in which the desire to be offered options is not automatically linked with the willingness of taking decisions or getting more knowledge.

\section{KEYWORDS}

Patients Preferences; Shared Decision Making;

Psychiatric Outpatients; Affective Disorders

\section{INTRODUCTION}

If psychiatry was an accurate science, there would be one proper answer for each mental health problem and the patients' preferences about treatments would be irrelevant to what is "right". But psychiatry is just an uncertain science with many clinical situations in which more than one reasonable possibility of intervention is available with no evidence that any of the alternatives is better than another.

Patient's participation in medical decision making has been increasingly advocated as a means to enhance selfdetermination and empowerment of patients [1]. Shared decision-making (SDM) is a patient-centered approach in which the healthcare professional and patient exchange information on the best available treatment and discuss the implications of each option [2-4]. In the process, patient autonomy is respected, the patient is assisted with setting their values and preferences, and final treatment decisions reflect a mutual agreement between patient and physician rather than a unilateral decision taken solely by the physician, or by the patient.

The model of shared decision making represents a promising possibility for increasing the autonomy of 
psychiatric patients and this autonomy encouragement could be an improvement in drug adherence [5,6]. In particular, poor adherence to pharmacologic treatment of affective disorders is a worldwide problem of striking magnitude that prevents patients from gaining access to the best treatment [7]. Moreover, involving psychiatric patients in therapeutic decisions help implement basic rights of a group of patients who have not sufficiently benefited from consumer empowerment in other medical fields.

However, not all patients are prepared, suitable, or want to participate to the same degree in the process of making decisions about the treatment of their disease. The suitability of a decision in SDM depends on the clinical context, patient preferences, and the responsibility of healthcare professionals [8]. Furthermore, making the right medical choices is harder than ever since patients are overwhelmed by information from all sides: their doctors' recommendations, dissenting expert opinions, confusing statistics, conflicting media reports, the advice of friends, claims on the internet, and a neverending stream of drug company ads [9]. In addition, patients may wish to participate in a variety of ways including seeking and exchanging information, discussing options in care, and making the final decisions about treatment. Some may want to play an active role in discussing treatment options, but ultimately want their doctors to be the ones who make decisions on their behalf [10]. For this reason, healthcare professionals and health organizations should not assume that patients want to participate in clinical decision-making, but must assess each patient's preferences and tailor care accordingly.

Questions about psychiatric patients' preferences remain unanswered. How much of them do embrace the collaborative model? Are there clinical and/or sociodemographic differences associated with such preferences? In order to measure different aspects of participation in decision making, psychiatric outpatients attending in a Community Mental Health setting expressed preferences ranging from patient-directed to psychiatristdirected styles on each of 3 aspects of decision making (seeking information, discussing options, making the final decision).

\section{MATERIAL AND METHOD}

\subsection{Sample}

From September 2011 to June 2012, one hundred and seventy-two consecutive psychiatric outpatients with affective disorders attended in two Community Mental Health Centres at Tenerife Island (Canary Islands, Spain) were invited to participate in the study. Each participant received a full explanation of the study, after which he or she signed an informed consent document that had been approved by the local ethics committee. Each participant then filled out a brief socio-demographic survey and the rest of the questionnaires.

\subsection{Measures}

\subsubsection{Socio-Demographic Characteristics and Clinical Variables}

Age, gender, educational level (no formal education, primary studies, secondary studies, and university degree), history as psychiatric patient (in years), and type of psychoactive drugs currently taken were assessed. For evaluation purposes the drugs were divided into the common groups of psychotropics: antidepressants (tricyclics, selective serotonin reuptake inhibitors-SSRIsand serotonin and norepinephrine selective reuptake inhibitors-SNRIs-), benzodiazepines, antipsychotics (conventional and atypical) and mood stabilizers. We also recorded how long patients had been under psychiatric treatment (in months), the number of different psychiatrists that have treated them during that time, and the number of psychiatric admissions specifying its voluntary or involuntary character. Psychiatrists responsible for patient' mental health care were asked about patient diagnosis and after patient consultation to give their impression on their patients adherence since the last clinic visit as well as scored the Clinical Global ImpressionSeverity scale (CGI-S) and the Clinical Global Impression-Improvement scale (CGI-I) [11]. The feeling of being informed about psychiatric medications was assessed by means of two dichotomous items: "Do you consider that you have enough information about your treatment?" and "Would you like to have more information about your medicines?" The way in which the patient perceived that his/her doctor considers his/her opinion about treatment was assessed with another dichotomous item: "Does your psychiatrist ask your opinion about the treatment that would be prescribed?"

\subsubsection{Preferences for Participating in Decision Making}

As a way to explore preferences for participating in decision making, we used three items developed by Levinson et al. [10], based on a review of several models of decision making. These questions assessed patients' participation preferences, and response options ranged from a patient-directed to a physician-directed style on three aspects of decision making (seeking information, discussing options and making the final decision). The response format was changed from the original six point scale to a four point Likert scale in which the respondent scores each item: strongly disagree (0), disagree (1), agree (2) or strongly agree (3). The items read as follows: “I prefer to rely on my doctor's knowledge and not try to find out about my condition on my own” (Knowledge); 
"I prefer that my doctor offers me choices and asks my opinion" (Options); "I prefer to leave decisions about my medical care up to my doctor” (Decision).

\subsection{Attitudes toward Treatment}

\subsubsection{Drug Attitude Inventory (DAI-10)}

The DAI [12] is a self-report scale developed to measure subjective responses and attitudes of psychiatric patients towards their treatment revealing whether the patients are satisfied with their medications and evaluating their understanding of how the treatment is affecting them. The original version of the scale consists of 30 items covering seven categories: subjective positive, subjective negative, health and illness, physician control, prevention, and harm. A shorter version consisting of 10 key items was subsequently developed (the DAI-10). The reduced version "DAI-10" has ten highly specific items of subjective experience presented as self-report statements with which the patient agrees or disagrees. These are based on the true recorded and transcribed accounts of patients, and response options are true/false only. These items were selected for their capacity to discriminate between medication adherence grades in a way that can be analyzed statistically. Each response is scored as +1 if correct or -1 if incorrect. The final score is the grand total of the positive and negative points. Its total score comprises values from -10 to 10 with higher scores indicating more positive attitude towards medication. A positive total score means a positive subjective response. A negative total score means a negative subjective response. The DAI-10 is concise, easy to administer, and its psychometric properties are well established. The scale has been shown to have test-retest reliability, high internal consistency, and discriminant, predictive, and concurrent validity [13]. Although the DAI was initially designed for schizophrenia, it has also been used to investigate treatment adherence in patients with affective disorders [14].

\subsubsection{Beliefs about Medicines Questionnaire (BMQ)}

The Beliefs about Medicines Questionnaire (BMQ) was developed in the United Kingdom by Horne et al. [15] and validated for psychotropics into Spanish by De las Cuevas et al. [16]. It comprises a general and a specific scale and each has two subscales. The BMQ General Scale assesses more general beliefs or social representations of pharmaceuticals as a class of treatment and includes eight items in two subscales of four items, Overuse and Harm. The BMQ-Specific scale assesses the patients' beliefs about the medication he/she is prescribed for a specific illness in terms of the necessity and concern about taking it. The scale includes 10 items in two subscales, Concern and Necessity, each of five items. The degree of agreement with each statement is indicated on a five point Likert scale, ranging from 1 = strongly disagree to 5 = strongly agree. BMQ have shown to be a valid and reliable measure and it is able to discriminate between different groups of patients [17-19].

\subsubsection{Leeds Attitude toward Concordance Scale (LATCon)}

The Leeds Attitude toward Concordance scale (LATCon) is a 12-item self-report scale, developed by Raynor et al. [20] and validated into Spanish by De las Cuevas et al. [21] that assessed patients' and health professionals' attitudes towards concordance in medicine-taking. The respondent scores each item on a four point Likert scale: strongly disagree (0), disagree (1), agree (2) or strongly agree (3). The total maximum score is therefore 36 . The higher the score in the scale, the more positive the respondent's attitude towards concordance. To facilitate interpretation, the total score is divided by the number of items leading to an average score per item. A mean item score of between 2 and 3 indicates that the respondent tends to "agree" with the concept of concordance, while an average score below 2 suggests that he/she does not do so. In order to specifically assess the agreement in a psychiatric context, the term "doctor" was replaced by "psychiatrist".

\subsection{Clinical Status}

\section{Beck Depression Inventory (BDI-II)}

The Beck Depression Inventory (BDI), created by Dr. Aaron T. Beck in 1961, is a 21-question multiple-choice self-report inventory, one of the most widely used instruments for measuring the severity of depression. The BDI-II was a 1996 revision of the BDI [22,23], developed in response to the American Psychiatric Association's publication of the Diagnostic and Statistical Manual of Mental Disorders, Fourth Edition, which changed many of the diagnostic criteria for Major Depressive Disorder. Items involving changes in body image, hypochondria, and difficulty working were replaced. Also, sleep loss and appetite loss items were revised to assess both increases and decreases in sleep and appetite. All but three of the items were reworded; only the items dealing with feelings of being punished, thoughts about suicide, and interest in sex remained the same. Finally, participants were asked to rate how they have been feeling for the past two weeks, as opposed to the past week as in the original BDI. Like the BDI, the BDI-II also contains 21 questions, each of the 21 items corresponds to a marker of depression and is scored by the subject on a four-point scale ( 0 - 3) according to the way the participant has been feeling in the previous 2 weeks. The 21 items are then summed to give a single total score for the BDI-II, for which cutoff scores have previously been established. The cutoffs used differ from the original: 0 - 
13: minimal depression; 14 - 19: mild depression; 20 - 28: moderate depression; and 29 - 63: severe depression. Higher total scores indicate more severe depressive symptoms. The BDI-II is a reliable and well-validated measure in screening for depression symptoms in adults, with Cronbach's alphas ranging from 0.73 to 0.95 .

\subsection{Statistical Methods}

Effects of socio-demographic and clinical characteristics on preferences were assessed using proportional odds regression models. We conducted a range of sensitivity analyses to ensure that conclusions were not dependent upon the specific statistical model selected. To contrast the patient opinion about participation preferences, chi square strategies were used. Correlation analysis was developed to know the relationship pattern among different preferences. Finally, discriminant analyses were performed to predict the patients' preferences.

\section{RESULTS}

We registered a high response rate of $85 \%$ resulting in a sample of 152 psychiatric outpatients with affective disorders. Table 1 shows the sample distribution according to socio-demographic and clinical variables included in the study. The percentage of patients who reported that they do not have enough information about their medicines was only $10 \%$ and $42 \%$ stated that they would like to get more information about it. Thirty-six percent stated that their psychiatrist does not ask them their opinion about their treatment.

Table 2 shows the distribution of responses to the 3 participation questions. It is remarkable that almost all psychiatric outpatients with affective disorders (91\%) preferred to leave final decisions to their psychiatrist and 87\% preferred to rely on psychiatrists for medical knowledge rather than seeking their own information, both responses indicative of a physician-directed style. In contrast, eighty-one percent of patients answered positively when asked whether they prefer to be offered options and to be asked their opinions by their doctors, indicative of patient-directed style.

The correlation among the three questions about preferences for participating in decision making was the first analysis. There was a mixed pattern: "knowledge" and "decision" were positive related: $r_{x y}=0.34 ; p=0.000$ (as more the patients believe in the psychiatrist knowledge, more they wish to participate in therapeutic decision); but "knowledge" and "decision" are independents of "options" knowledge $\left(r_{x y}=0.04\right.$; and $r_{x y}=0.03$, respectively). These results suggest that preference of psychiatric outpatients with affective disorders for participation in their medical decisions is not a single-dimensional construct, supporting the idea that could consist of
Table 1. Socio-demographic and clinical characteristics of the sample studied.

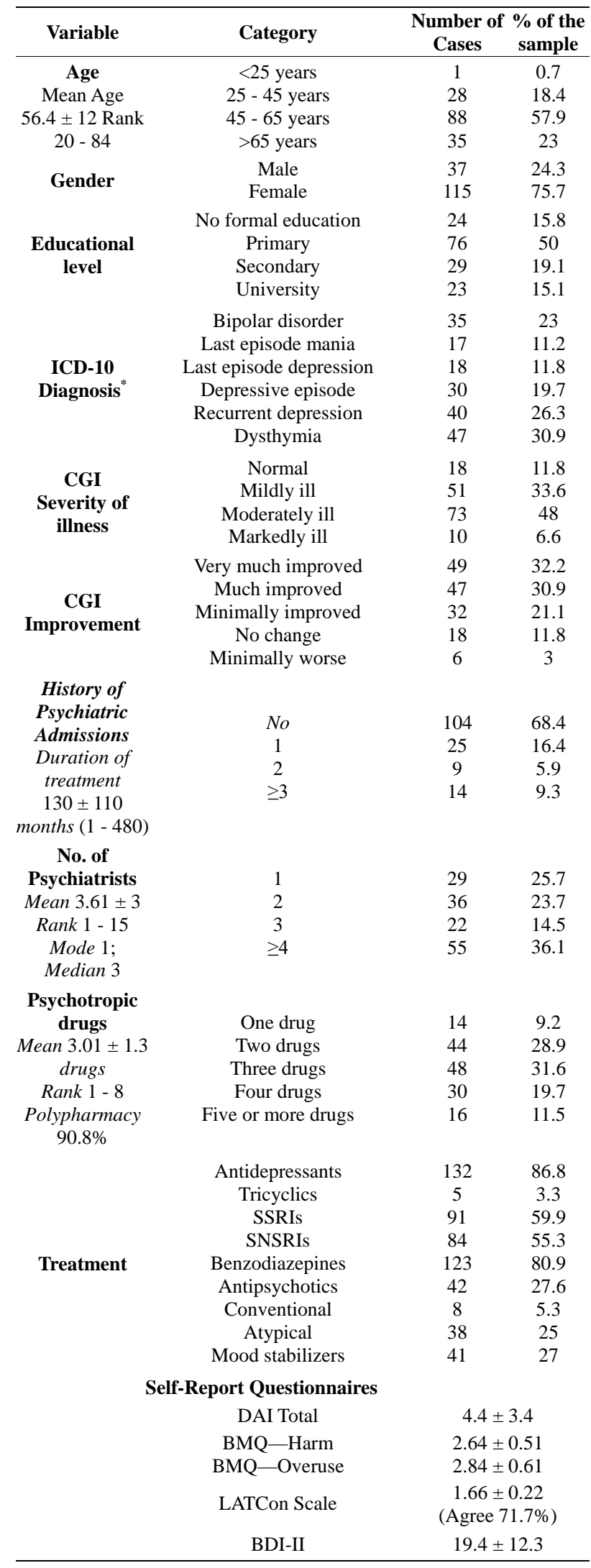


Table 2. Psychiatric outpatients' preferences for participation in decision making.

\begin{tabular}{cccc}
\hline & Knowledge (\%) & Options (\%) & Decision (\%) \\
\hline Totally disagree & 0 & 0.7 & 0.7 \\
Disagree & 13.2 & 18.4 & 8.6 \\
Agree & 84.2 & 78.9 & 89.5 \\
Totally agree & 2.6 & 2.0 & 1.3 \\
$\mathbf{X}^{2}$ & $179.58^{* * *}$ & $247.84^{* * *}$ & $339.32^{* * *}$ \\
\hline
\end{tabular}

Knowledge: "I prefer to rely on my doctor's knowledge and not try to find out about my condition on my own"; Options: "I prefer that my doctor offers me choices and asks my opinion"; Decision: "I prefer to leave decisions about my medical care up to my doctor"; $\mathrm{X}^{2}=$ chi square; ${ }^{* * *}=\mathrm{p}=$ 0.000 .

the three distinct components considered: options, knowledge, and decisions.

In order to know the overall pattern of the opinion of depressive patients about participation preferences, the answer alternatives were transformed in nominal variables: "strongly disagree", and "disagree" into a general category of "disagreement"; and "agree", and "strongly agree" into a general category of "agreement". According these transformations, patient profiles were performed about if they preferred a "psychiatrist directed approach" or "patient directed approach" taking into account the three variables. Table 3 summarizes those profiles.

Only $2.6 \%$ of psychiatric outpatients with affective disorders preferred a patient directed approach across all 3 dimensions and $15.8 \%$ across two dimensions. Psychiatrist directed approach across the three dimensions considered was preferred by $18.7 \%$ while $63.9 \%$ across two dimensions.

In order to know if there are variables that explain why the depressive sample prefers to participate or no in decision making, three discriminant analyses were carried out, taking Disagreement/Agreement classification as group variables. Predicting variables were both socio-demographic variables: sex, age, level of education, marital status, employment situation, number of different psychiatrists, number of different medicines, and treatment duration; and personal/psychological variables: attitudes about medicines (DAI scale), belief about medicines (harmful and overuse subscales), concordance (LATcon scale), and depression level (BDI-II scale).

The three discriminant functions obtained reached statistical significance: Knowledge (Wilks' lambda $=0.78$; $\mathrm{X}^{2}(13)=36.32, \mathrm{p}=0.001$ ); Options (Wilks' lambda = $0.81 ; \mathrm{X}^{2}(13)=30.40, \mathrm{p}=0.004$ ); and Decisions (Wilks' lambda $\left.=0.95 ; X^{2}(13)=7.06, p=0.008\right)$. In Table 4 are summarized the variables and the discriminant coefficients (standardized) into the three functions (in bold are highlighted the coefficients equal or greater than 0.40).

As it can be observed, the percentages of cases correctly classified are similar for the three variables (be-
Table 3. Patients' preferences responses across the three dimensions.

\begin{tabular}{cccccc}
\hline & n & $\%$ & Knowledge & Options & Decision \\
\hline $\begin{array}{c}\text { Psychiatrist } \\
\text { directed } \\
\text { approach }\end{array}$ & 27 & 18.7 & Psy & Psy & Psy \\
& 1 & 0.7 & Psy & Pat & Psy \\
& 14 & 9.2 & Pat & Psy & Psy \\
$\begin{array}{c}\text { Patient } \\
\text { directed }\end{array}$ & 9 & 5.9 & Psy & Pat & Psy \\
approach & 1 & 0.7 & Pat & Psy & Pat \\
& 4 & 2.6 & Pat & Pat & Pat \\
\hline
\end{tabular}

Knowledge: "I prefer to rely on my doctor's knowledge and not try to find out about my condition on my own"; Options: "I prefer that my doctor offers me choices and asks my opinion"; Decision: "I prefer to leave decisions about my medical care up to my doctor".

Table 4. Standardized coefficients of the three discriminant functions for the three preferences variables.

\begin{tabular}{|c|c|c|c|}
\hline Variables & Knowledge & Options & Decision \\
\hline Sex & 0.49 & 0.14 & -0.04 \\
\hline Age & 0.50 & 0.30 & -0.13 \\
\hline Marital status & -0.28 & -0.17 & 0.24 \\
\hline Education level & -0.14 & -0.04 & 0.57 \\
\hline Treatment duration & -0.06 & -0.28 & -0.11 \\
\hline $\begin{array}{l}\text { Number of different treating } \\
\text { psychiatrists }\end{array}$ & -0.30 & 0.27 & 0.15 \\
\hline Number of different medicines & 0.09 & 0.54 & -0.07 \\
\hline $\begin{array}{l}\text { Attitudes about medicines (DAI } \\
\text { scale) }\end{array}$ & 0.18 & -0.11 & -0.31 \\
\hline $\begin{array}{l}\text { Belief about medicines } \\
\text { (harmful subscale) }\end{array}$ & -0.23 & 0.36 & -0.34 \\
\hline $\begin{array}{l}\text { Belief about medicines } \\
\text { (overuse subscale) }\end{array}$ & -0.41 & 0.24 & 0.65 \\
\hline Concordance (LATCon scale) & 0.23 & 0.63 & -0.05 \\
\hline Level of depression (BDI scale) & 0.38 & -0.37 & -0.26 \\
\hline$\%$ cases correctly classified & 78.8 & 74.8 & 70.1 \\
\hline
\end{tabular}

tween $70 \%-80 \%$ ), but there are different weights for each predicted variable. The consideration of patients about the credibility on psychiatrist's knowledge about their disorder is especially related with "age" (there is greater confidence in older patients), sex (men are more confident), and with the belief about an excessive use of medicines (negative relationship). With respect to the patient preferences about psychiatrists offering them different options about how to deal with depression, there are more preferences especially when they have a more positive attitude about patient-professional concordance and when they take more different medicines. Finally, in shared decision making about treatment, there was an especially psychiatry direct approach with beliefs about an excessive use of medicines, with higher level of education. 


\section{DISCUSSION}

According to our results, psychiatric outpatients with affective disorders from our health care setting preferred, at present time, mainly to play a passive role and set their psychiatrists in positions of dominance and authority. It seems necessary to encourage patients in a more balanced partnership in medical decision making since the benefits of increased patient participation have been widely demonstrated.

Patients with depressive disorders prefer to know all the options available about their treatment but rely on knowledge of their psychiatrist and delegate final decisions on them. When facing a depressive disorder, making even simple decisions can become a major undertaking, and more difficult decisions can become impossible. It is well established that depressed individuals tend to focus their attention on unhappy and unflattering information, to interpret information negatively, and to harbour pervasively pessimistic beliefs [24-26]. Negative thinking is not only a concomitant or symptom of depression it is also a causal antecedent of depression since cognitive biases precede and give rise to depressive symptoms [27].

The variable "options" keeps some independence from relying on the expertise knowledge of their psychiatrists and especially with the final decision-making. This may indicate that such people do not want really to know the options they have in order to participate in subsequent decision making, but as a way of knowing that their problem is tractable (in different ways) and that would be valuable in itself to them. An alternative explanation could be that offering options by the psychiatrist is perceived by the patients as a demonstration of interest by the psychiatrists in their personal cases as well as a demonstration of technical abilities of the mental health professional to sort out different options of treatment and choosing the best for the patient.

Although a great majority of the patients desired a passive decision-making role, preferences of participation varied according patient characteristics.

The profile of psychiatric outpatients with affective disorders that prefer to be offered options and to be asked their opinions by their doctors, indicative of patient-directed style, is well characterized by three main determinants: the greater number of different psychoactive medications a patient use, the more harmful the patient thinks the psychiatric medications are and the more favourable is his/her attitude toward concordance with medication-taking more.

There are also some conditioning variables related to the dimension "knowledge" of shared decision making. The patients that are more confident in the expertise of their psychiatrists are men, older patients and those who consider that there is not an overuse of medicines. Even patients who scored higher on the BMQ-Overuse scale, thinking that psychiatric drugs are prescribed in excess, were less confident in the knowledge of psychiatrists (negative relationship with knowledge dimension), and as they take more medicines more options of treatment they want to know by their psychiatrists. But, finally, they still want to be psychiatrists who take the final decision (positive with decision), probably overwhelmed by the number of drugs.

Finally, although previous studies have demonstrated that high level education is a determinant of preference for shared decision making $[28,29]$, our results nevertheless showed that the higher the patients' educational level is the more they preferred to leave final decisions to their psychiatrist. Paraphrasing David Byrne "The more you know, the more you know you don't know and the more you know that you don't know".

\section{CONCLUSION}

Mental health care of affective disorders presents aspects that might differ from treatment decision-making for other types of health conditions. Shared decision making approach of patients with affective disorders must take into consideration a more doctor-oriented approach preferred by the patients in which the desire of to be offered options is not automatically linked with the willingness of taking decisions-or even been involved on it-or getting more knowledge. In any case, this profile must be balanced against the temptations of a more paternalistic approach in the management of these patients. Among the more traditional paternalism and the more extreme autonomism, there is a wide range of possibilities and patients have the right to choose.

\section{ACKNOWLEDGEMENTS}

This work was funded by the Instituto de Salud Carlos III, FEDER Union Europea (Grant No. PI10/00955).

\section{REFERENCES}

[1] Edwards, A. and Elwyn, G. (2009) Shared decisionmaking in health care: Achieving evidence-based patient choice. 2nd Edition, Oxford University Press, Oxford, New York.

[2] Charles, C., Gafni, A. and Whelan, T. (1997) Shared decision-making in the medical encounter: What does it mean? (or it takes at least two to tango). Social Science \& Medicine, 44, 681-692.

http://dx.doi.org/10.1016/S0277-9536(96)00221-3

[3] Elwyn, G., Edwards, A., Gwyn, R. and Grol, R. (1999) Towards a feasible model for shared decision making: Focus group study with general practice registrars. $B M J$, 319, 753-756.

http://dx.doi.org/10.1136/bmj.319.7212.753 
[4] Makoul, G. and Clayman, M.L. (2006) An integrative model of shared decision making in medical encounters. Patient Education and Counseling, 60, 301-312. http://dx.doi.org/10.1016/j.pec.2005.06.010

[5] Horne, R. and National Coordinating Centre for NHS Service Delivery and Organisation (Great Britain) (2005) Concordance, adherence and compliance in medicine taking: Report for the National Coordinating Centre for NHS Service Delivery and Organisation R \& D (NCCSDO). NCCSDO, London.

[6] De Las Cuevas, C. (2011) Compliance, adherence and concordance in medicine taking of psychiatric patients. Current Clinical Pharmacology, 6, 71-73. http://dx.doi.org/10.2174/157488411796151165

[7] Sabaté, E. (2003) Adherence to long-term therapies evidence for action. World Health Organization, Geneva.

[8] Trevena, L. and Barratt, A. (2003) Integrated decision making: Definitions for a new discipline. Patient Education and Counseling, 50, 265-268.

http://dx.doi.org/10.1016/S0738-3991(03)00047-8

[9] Groopman, J.E. and Hartzband, P. (2011) Your medical mind: How to decide what is right for you. Penguin Press, New York.

[10] Levinson, W., Kao, A., Kuby, A. and Thisted, R.A. (2005) Not all patients want to participate in decision making. A national study of public preferences. Journal of General Internal Medicine, 20, 531-535. http://dx.doi.org/10.1111/j.1525-1497.2005.04101.x

[11] Guy, W. (1976) Early Clinical Drug Evaluation Unit (ECDEU) assessment manual for psychopharmacology. National Institute of Mental Health, Bethesda.

[12] Hogan, T.P., Awad, A.G. and Eastwood, R. (1983) A self-report scale predictive of drug compliance in schizophrenics: Reliability and discriminative validity. Psychological Medicine, 13, 177-183. http://dx.doi.org/10.1017/S0033291700050182

[13] Hogan, T.P. and Awad, A.G. (1992) Subjective response to neuroleptics and outcome in schizophrenia: A re-examination comparing two measures. Psychological Medicine, 22, 347-352. http://dx.doi.org/10.1017/S0033291700030282

[14] Vieta, E., Blasco-Colmenares, E., Figueira, M.L., Langosch, J.M., Moreno-Manzanaro, M., Medina, E. and WAVE-bd Study Group (2011) Clinical management and burden of bipolar disorder: A multinational longitudinal study (WAVE-bd study). BMC Psychiatry, 11, 58. http://dx.doi.org/10.1186/1471-244X-11-58

[15] Horne, R., Weinman, J. and Hankins, M. (1999) The beliefs about medicines questionnaire: The development and evaluation of a new method for assessing the cognitive representation of medication. Psychology and Health, 14, 1-24.

http://dx.doi.org/10.1080/08870449908407311

[16] De las Cuevas, C., Rivero-Santana, A., Perestelo-Pérez, L., González-Lorenzo, M., Pérez-Ramos, J. and Sanz, E.J. (2011) Adaptation and validation study of the beliefs about medicines questionnaire in psychiatric outpatients in a community mental health setting. Human Psychopharmacology: Clinical and Experimental, 26, 140-146.

\section{http://dx.doi.org/10.1002/hup.1185}

[17] Horne, R. and Weinman, J. (1999) Patients' beliefs about prescribed medicines and their role in adherence to treatment in chronic physical illness. Journal of Psychosomatic Research, 47, 555-567. http://dx.doi.org/10.1016/S0022-3999(99)00057-4

[18] Beléndez, M., Hernández, A., Horne, R. and Weinman, J. (2007) Evaluación de las creencias sobre el tratamiento: Validez y fiabilidad de la versión española del Beliefsabout Medicines Questionnaire. International Journal of Health \& Clinical Psychology, 7, 767-779.

[19] Mahler, C., Hermann, K., Horne, R., Jank, S., Haefeli, W.E. and Szecsenyi, J. (2012) Patients' beliefs about medicines in a primary care setting in Germany. Journal of Evaluation in Clinical Practice, 18, 409-412. http://dx.doi.org/10.1111/j.1365-2753.2010.01589.x

[20] Raynor, D.K., Thistlethwaite, J.E., Hart, K. and Knapp, P. (2001) Are health professionals ready for the new philosophy of concordance in medicine taking? International Journal of Pharmacy Practice, 9, 81-84. http://dx.doi.org/10.1111/j.2042-7174.2001.tb01034.x

[21] De las Cuevas, C., Rivero, A., Perestelo-Perez, L., Gonzalez, M., Perez, J. and Peñate, W. (2011) Psychiatric patients' attitudes towards concordance and shared decision making. Patient Education and Counseling, 85, e245e250. http://dx.doi.org/10.1016/j.pec.2011.02.015

[22] Beck, A.T., Steer, R.A., Ball, R. and Ranieri, W. (1966) Comparison of Beck Depression Inventories-IA and -II in psychiatric outpatients. Journal of Personality Assessment, 67, 588-597. http://dx.doi.org/10.1207/s15327752jpa6703_13

[23] Sanz, J., García, M.P., Espinosa, R., Fortún, M. and Vázquez, C. (2005) Adaptación española del Inventario para la Depresión de Beck-II (BDI-II): 3. Propiedades psicométricas en pacientes con trastornos psicológicos. Clínica y Salud, 16, 121-142.

[24] Hollon, S.D., Kendall, P.C. and Lumry, A. (1986) Specificity of depressotypic cognitions in clinical depression. Journal of Abnormal Psychology, 95, 52-59. http://dx.doi.org/10.1037/0021-843X.95.1.52

[25] Krantz, S.E. and Rude, S.S. (1984) Depressive attributions: Selection of different causes or assignment of dimensional meanings? Journal of Personality and Social Psychology, 47, 193-203. http://dx.doi.org/10.1037/0022-3514.47.1.193

[26] Rude, S.S., Krantz, S.E. and Rosenhan, D.L. (1988) Distinguishing the dimensions of valence and belief consistency in depressive and nondepressive information processing. Cognitive Therapy and Research, 12, 391-407. http://dx.doi.org/10.1007/BF01173306

[27] Rude, S.S., Wenzlaff, R.M., Gibbs, B. and Vane, J. (2002) Negative processing biases predict subsequent depressive symptoms. Cognition and Emotion, 16, 423-440. http://dx.doi.org/10.1080/02699930143000554

[28] Benbassat, J., Pilpel, D. and Tidhar, M. (1998) Patients' preferences for participation in clinical decision making: A review of published surveys. Behavioral Medicine, 24, 81-88. http://dx.doi.org/10.1080/08964289809596384 
[29] Carlsen, B. and Aakvik, A. (2006) Patient involvement in clinical decision making: The effect of GP attitude on patient satisfaction. Health Expect, 9, 148-157. http://dx.doi.org/10.1111/j.1369-7625.2006.00385.x 